\title{
¿QUÉ SIGNIFICA LA ACREDITACIÓN DE ALTA CALIDAD PARA NUESTROS HOSPITALES?
}

\author{
Jorge Gómez Cusnir MD*
}

Quiero compartir con ustedes no sólo la buena noticia de que he recibido oficialmente la notificación por parte de la junta de acreditación en salud el pasado 18 de marzo del año en curso y ratificada por el Consejo Directivo del ICONTEC. Una vez analizado el informe de visita de evaluación complementaria y con base en el Decreto 1011 y la Resolución 1445 de 2006, se aprobó el otorgamiento del Certificado de Acreditación en la categoría de Institución Acreditada en Salud a la Sociedad de Cirugía de Bogotá-Hospital de San José, lo que representa el reconocimiento al trabajo adelantado durante años por esta gran familia de nuestro Hospital de San José y todo el talento humano, principal activo estratégico y factor diferenciador de nuestras instituciones en el sector de la salud y la educación.

Este reconocimiento y el esfuerzo que ha realizado nuestra organización para alcanzarlo, enaltece los logros ya recibidos por el Hospital Infantil Universitario de San José en el mes de enero de 2013 cuando recibió la certificación de institución acreditada en salud, así como la acreditación de los programas de pregrado de las facultades de medicina, enfermería e instrumentación quirúrgica de la Fundación Universitaria de Ciencias de la Salud, por parte del Ministerio de Educación y el Consejo Nacional de Acreditación.

La acreditación de alta calidad es mucho más que un certificado, representa el compromiso y el reconocimiento de que nuestras organizaciones tienen inmerso en su ADN institucional una cultura de autoevaluación, medición y seguimiento a un gran número de indicadores de gestión, que determinan el reconocimiento de oportunidades y planes estructurados de mejoramiento continuo en todas las áreas. La gestión eficiente y eficaz de los procesos organizacionales que un ente evaluador externo revisa y certifica el cumplimiento a cabalidad de cada uno de

\footnotetext{
* Presidente de la Sociedad de Cirugía de Bogotá-Hospital de San José, institución acreditada en salud.
}

los cientos de estándares, representan compromisos ineludibles con el Sistema Único de Acreditación en Salud, que es un componente del sistema de garantía de calidad establecido en el decreto 1011 y la resolución 1445 de 2006.

Este logro, que es un paso fundamental en nuestras aspiraciones de continuar siendo reconocidos como hospital universitario, es el mensaje directo a la comunidad de que continuamos con nuestro compromiso con la calidad en la prestación de los servicios y la seguridad clínica, representado en una cultura organizacional que gestiona los riesgos, la tecnología, su infraestructura y su talento humano, para que nuestros pacientes y sus familias reciban un trato humanizado con todos los atributos de la calidad.

Como promovemos la responsabilidad social empresarial y el mejoramiento continuo desde nuestro direccionamiento estratégico, son de vital importancia estos procesos porque generan una cultura de seguimiento, de documentación y reporte, lo que permite a la alta dirección ejercer control y tomar decisiones con base en indicadores e información clara, oportuna y veraz. Así mismo se generan planes de mejora, se asignan recursos y en general se tiene una mejor visión y conocimiento de la organización. Con ello se consigue el reconocimiento y la gestión de los riesgos por parte de las distintas personas y el equipo de trabajo, lo que al final produce mejores resultados y satisfacción de los pacientes y sus familias que reciben nuestros servicios, generando valor agregado y un diferencial competitivo a nuestros hospitales, que al final se ven reflejados en ahorros importantes en costos y mejores indicadores de gestión médicos y administrativos para beneficio de todo el grupo empresarial.

No hemos sido inferiores a nuestro legado, con responsabilidad y compromiso hemos obtenido un merecido reconocimiento a una labor que se inició hace varios años por convicción y política de las 
Juntas Directivas desde el año 2000, siendo directora la doctora Laima Didziulis cuando participamos en el premio nacional a la calidad, seguida en 2006 con lujo de detalles por el director del hospital el doctor Carlos Humberto Pérez y su equipo, ya inmersos en un proceso con el Centro de Gestión Hospitalaria y luego con la colaboración de FDF Consulting como grupo asesor, y que en los últimos años ha sido la responsabilidad y compromiso, también con un extraordinario trabajo del doctor Luis Alberto Blanco y sus colaboradores.

La acreditación de nuestros hospitales universitarios es una clara respuesta de nuestro compromiso con la comunidad, con nuestra institución universitaria que podrá en adelante continuar su proceso de desarrollo y crecimiento, tranquila y soportada por sus dos hospitales ya acreditados, lo que constituye su verdadera ventaja competitiva en el ámbito nacional e internacional.

Con verdadero valor patrio nuestro Hospital de San José ha escrito en letras de molde los más bellos episodios de la historia médica de nuestro país. Miles de profesionales egregios han sido formados en esta escuela del saber médico, construyendo paso a paso una escuela médicoquirúrgica del más alto reconocimiento en la comunidad científica colombiana.

Las dificultades económicas y la iliquidez han sido el diario vivir de nuestra institución docente asistencial, debido a los cambios frecuentes durante todos estos años en los esquemas de contratación y los servicios prestados a los distintos actores del sistema, conforme han hecho su aparición en este agitado sector de la salud, cuyas actividades y gestión han sufrido todo tipo de reglamentaciones cambiantes, leyes y decretos, que poco a poco han hecho mella en las finanzas y en la viabilidad de los grandes hospitales universitarios privados o públicos, que aún mantienen sus puertas abiertas.

Debo no solo reconocer, sino también agradecer a los compañeros de la Junta Directiva comprometidos y alineados integralmente con el proceso de autoevaluación, mejoramiento continuo y políticas de direccionamiento, que junto con el enorme esfuerzo y liderazgo que en este proceso de varios años asumió como cabeza de este equipo la dirección del hospital con el doctor Luis Alberto Blanco, la subdirección médica con la doctora Silvia Mora, el grupo de garantía de calidad, liderado por la doctora Diana García y la jefe Ángela Agudelo en acreditación, la gerencia del hospital con el doctor Santiago Barragán y todo el equipo administrativo y el departamento de enfermería con el liderazgo de la licenciada Margarita Pérez. Es justo reconocer también el compromiso del cuerpo médico, los jefes de los departamentos y servicios siempre dispuestos a colaborar en este proceso de mejora continua, así como el de todos los colaboradores paramédicos y de servicios de apoyo.

En adelante es mayor el esfuerzo y el compromiso para poder mantener los estándares de calidad, la cultura organizacional de autoevaluación y mejoramiento continuo, para que en las próximas visitas de seguimiento por parte de ICONTEC, ya anunciadas, podamos demostrar que este reconocimiento no ha sido una meta específica, sino el resultado de lo que es y seguirá siendo nuestra cultura institucional y nuestro Hospital de San José.

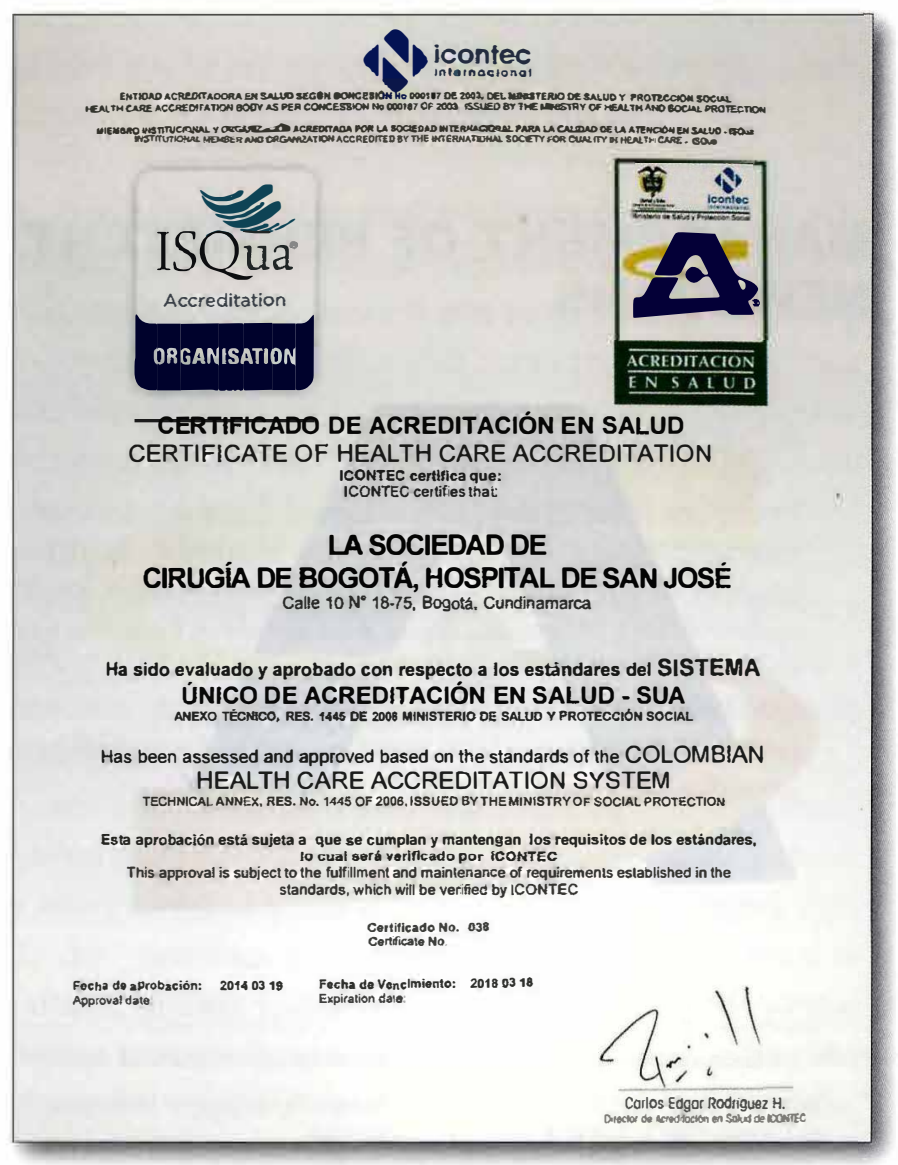

